\title{
Rabies Elimination Program of Bangladesh
}

\author{
Moazzem Hossain
}

\begin{abstract}
Chairman, Institute of Allergy \& Clinical Immunology of Bangladesh (IACIB), Dhaka; Director, Filaria and General Hospital, Savar, Dhaka, Bangladesh; Professor of Microbiology and Former Director, Communicable Disease Control and Line Director, Directorate General of Health Services, Ministry of Health \& Family Welfare, Dhaka, Bangladesh; Cell no.: +8801715038551, Email: moazzem.iacib@gmail.com
\end{abstract}

Rabies is one of the major public health concerns. Before 2010 more than 2000 rabies related death were estimated to occur in Bangladesh ${ }^{1}$. Domestic dog is the single most important cause of transmitting rabies in Bangladesh followed by cat and jackal. There is an estimated 1.6 million dog population in Bangladesh with over $80.0 \%$ of them being free roaming and these dogs causes around 3 to 4 hundred thousand human cases and that of around 50 thousand cattle annually ${ }^{2}$.

Considering the public health impact of human rabies, Communicable Disease Control (CDC) unit of Directorate General of Health Services (DGHS) under the Ministry of Health and Family Welfare (MOHFW), Peoples Republic of Bangladesh has been created a program named as National Rabies Control Program in the year of 2009 which has been implementing the National Rabies Control Program since 2010 to control rabies by 2020 in collaboration with Department of Livestock (DLS), Local Government, Non-Government organizations (NGOs), Development partners ${ }^{3}$.

There has been very good planning, strong intersectorial coordination and successful implementation through ministerial level, multisectorial National Steering Committee (NSC), National Technical Working group (NTWG) by adopting a National strategy and National Action Plan. In 2017, the National Rabies Control program became prioritized as a separate program under CDC, DGHS and the goal has been shifted from control to elimination. The main strategic components are advocacy, communication and social mobilization, management of animal exposure cases, mass dog vaccination (MDV), surveillance with research and management of dog population ${ }^{4}$.
The program is running progressively towards its target of elimination of rabies by 2022 with an adequate financial allocation to accomplish the strategic target activities and made significant achievements.

A total of 67 of Rabies Prevention and Control Centers (RPCC) with one at national level and at least one at each of the 64 districts of the country have been functioning. CDC, DGHS is providing PEP with free intra-dermal rabies vaccine (ID-RV) and rabies immunoglobulin (RIG) by trained physicians and nurses. Over the last 8 years, awareness of people has significant increase with more than $80.0 \%$ of the people seeking modern animal bite management throughout the country ${ }^{5}$. MDV has been adopted as the main strategic component for achieving elimination of rabies. Since piloting at Cox's Bazaar in November 2011 MDV has been scaled up to all district municipalities adopting a short duration campaign and snow ball technique for increasing capacity especially in reference to dog catcher. The program has around 3 thousand dog catchers with some of them have wide experience in conducting MDV campaign. The short duration campaign has been proved to be very effective, more feasible and easily scalable.

Based on progressively built capacity and the experiences gathered, MDV campaign has been accomplished at least one round in 13 districts and in all the district municipalities, two rounds in 2 districts and three rounds, in Cot's Bazaar vaccinating around 0.65 million dogs with average coverage of $70.0 \%$ cases $^{4}$. The country capacity of conducting MDV is becoming stronger and currently capable to conduct the campaign in 4 or more districts simultaneously. 
Through increasing coverage of management of animal exposure and MDV campaign there has been significant decline in human rabies incidence over the last few years as demonstrated through survey, hospital records. In a national survey conducted in 2012 , estimated number of human rabies case was found to be 2007 and infectious Disease Hospital showed a declining report of rabies cases from 167 in to 53 in $2017^{2}$. Though national survey was not conducted recently, there is an assumption of reduction of human rabies to less than 200 as demonstrated by the hospital reports. Despite of various challenges, the national REP of Bangladesh has already been achieved strong political commitment, adequate allocation, strategy guided activities and one health approach through multisectorial collaboration to combat the disease.

Dog bite reporting from all the RPCC through DHIS2 is in place. However, lab diagnosis of rabies both in human and animal is yet to be established. There is a lab for animal rabies with Livestock department that requires further strengthening for diagnosis and collection and transportation of samples from the field. Establishment of a human rabies diagnostic laboratory in National Institute of Neuroscience is under active consideration and the program is working for development of a guideline and SOPs for this purpose. Different development partners including WHO, WAP, OIE, FAO, CDC have extended their supports in different capacities and works closely with Rabies Elimination program in
Bangladesh $^{5}$. Rabies elimination program of Bangladesh has achieved a significant progress in management of animal exposure, MDV and reduction of rabies. To achieve elimination of rabies by 2022 and rabies free status the country needs completion of 3 rounds of MDV campaign and strong disease surveillance. At the juncture, the program seeks review of the REP in Bangladesh to assess the strength and gap and also explore the possibility to brand it as a model for other countries with similar situation and specifically for countries of South Asia.

\section{References}

1. Ghosh S, Rana MS, Islam MK, Chowdhury S, Haider N, Kafi MA, et al. Trends and clinico-epidemiological features of human rabies cases in Bangladesh 2006-2018. Scientific reports. 2020;10(1):1-1

2. Li AJ, Sreenivasan N, Siddiqi UR, Tahmina S, Penjor K, Sovann L, et al. Descriptive assessment of rabies post-exposure prophylaxis procurement, distribution, monitoring, and reporting in four Asian countries: Bangladesh, Bhutan, Cambodia, and Sri Lanka, 2017-2018. Vaccine. 2019;37:A14-9 3. Alam AN, Siddiqua M, Casal J. Knowledge and attitudes about rabies in dog-bite victims in Bangladesh. One Health. 2020:100126.

4. Chowdhury FR, Basher A, R Amin M, Hassan N. Rabies in South Asia: fighting for elimination. Recent Patents on AntiInfective Drug Discovery. 2015;10(1):30-4

5. Gongal G, Wright AE. Human rabies in the WHO Southeast Asia Region: forward steps for elimination. Advances in preventive medicine. $2011 ; 2011$

[Bangladesh Journal of Infectious Diseases, December 2020;7(2):34-35] 